\title{
The Teaching Profession: A Networked Profession in New Networked Environments
}

\author{
Bernard Cornu \\ La Villa Media, Grenoble, France \\ bernard.cornu@la-metro.org
}

\begin{abstract}
The information and communication society is a networked society. We reflect on the concept of a network and identify some profound changes in society.

In such a society, knowledge is changing, new knowledge appears, and the structuring of knowledge is evolving. Access to knowledge is changing. The networked form of knowledge makes an evolution of educational systems and structures towards a networked organisation necessary. Complexity, which is a key characteristic of new knowledge in the new society, is reinforced and structured by networks.
\end{abstract}

The teacher's role is becoming more and more complex. We analyse some of the ways it is evolving, see how new technologies force us to confront the core roles of the teacher and reinforce some specific aspects of his/her profession, particularly the role as a mediator, and the role in the development of the collective intelligence.

The teacher is now dealing differently with time and space; he/she uses new learning environments, which are more global and link pedagogy and school life within its whole. The growing complexity and the changes in education lead not only to an evolving teaching profession, but also to new teaching professions.

Starting from different possible scenarios for the school of the future, we suggest possible scenarios for the teacher of the, future, and see the teacher's place in national policies.

ICT makes teaching more and more a profession, not only a vocation. The question now is not only to improve education with the help of ICT, but also to transform education and learning, as society is transformed.

The original version of this chapter was revised: The copyright line was incorrect. This has been corrected. The Erratum to this chapter is available at DOI: 10.1007/978-0-387-35701-0_35 
Information and Communication Technology (ICT) has a profound impact on Society and on Education. ICT not only provides new and supplementary tools able to help improve teaching or learning; it profoundly transforms Society, Education and Knowledge. The teaching profession is at the core of such changes, and is itself transformed by ICT. The role of the teacher is changing, the way the teacher works is changing. We have to distinguish the essential components of the teaching profession, the ones that are stable, and the ones that are changing. And we have to try to anticipate the main changes, in order not to be merely subjected to them, but to master and direct them.

\section{A NETWORKED SOCIETY}

A major change brought by ICT is networking. Most of our organisations, which were before of a hierarchical type ('tree-type' or 'pyramid-type'), are now moving to networks.

A network is a set of nodes and edges, the edges linking the nodes. It is a complex organisation, and a continuously evolving set. ICT has hugely increased the possibility of linking people, and linking objects. A complex network is progressively being elaborated, making our society a networked society. The Internet is one of the visible parts of the networked society; it links mainly computers, and, behind these computers, sites and people.

A network has important properties. The main one is that there are always several paths for going from one node to another (in a pyramidal structure, there is only one path from one point to another).

Let us look at some examples:

- Accessing an item of information in a book. In a traditional organisation, one had to use a 'hierarchical' path, going through bibliographies, library directories, name of the author, title of the book, table of contents, chapter number, page number, etc. In a networked system (like the Internet and with the use of search engines), one can access directly one word, one concept, one sentence in a book, without even going through the title of the book or the author's name.

- Communicating with people in a hierarchical system requires knowledge of the structure, the hierarchy and the rules. You can communicate with some people through other people, you often communicate with a 'function', not necessarily a person. In a networked system with tools like e-mail, one can communicate directly with a person, without knowing his/her position, his/her location, etc.

- Our educational systems are organized on a 'pyramidal type' basis: at the top, the Minister of Education, then Directors, Inspectors, principals, 
head teachers, teachers, pupils.... The pupils are organised in classrooms. One can think that in the networked society, such an organisation cannot be satisfying, and that new types of organisations will appear in educational systems, based on network principles.

Networks are permanently enriching and are becoming increasingly complex. Let us consider the Internet: Each web site is usually built according to a 'tree' structure. But one can create many new links, enriching the circulation in the 'tree', and each web site progressively becomes a kind of network between pages, resources, information ... and the set of all web sites makes a huge network, whose complexity is permanently growing, and with new nodes and new edges appearing at each moment.

A network can be considered in different ways. One can network people, and thus constitute a group of people who are connected in a network system. One can network information, and obtain a huge Information Network. In reality, we often think in a mixed way, linking people with people, people with information, information with other information.

There is not only one network, but there are many of them: local networks, particular networks ... they can themselves be networked, in order to create bigger networks, up to the 'global network', the network of networks...

For technologists, the links are important. For users, it is the nodes that are important: the people to connect, the information to connect. Merckelbach and Dupas (2002) suggest the metaphor of the spider and the giraffe. In a spider's web, what is important is the threads, and in between there is only emptiness. But if we look at a giraffe's skin, we see stains with lines in between, and it forms a network in which the important element is the stains. A network aims at connecting people, connecting information, and what is connected is more important than the edges connecting them. But the way they are connected is important as well: it creates proximities, it creates sub-networks, it creates new relationships.

In all domains, the network structure of society has consequences for the economy, social life, leisure, politics, etc. In education, it has major consequences, for knowledge itself, for the way one can access knowledge, for educational systems, for teaching and learning, and particularly for the teaching profession. 


\section{NEW KNOWLEDGE, NEW ACCESS TO KNOWLEDGE}

ICT changes knowledge itself. This is clear within each discipline, and one can easily describe such changes. Concepts, processes, methods, and resources available are evolving under the effect of ICT.

One must be careful not to confuse information and knowledge. Information is a raw object, most of the time independent of people. Knowledge is more elaborated: at the society level, it is a constituted set of information, with its own coherence, linked with main issues or questions, and linked with possible uses.

The Internet is at first a network of information. Education needs networks of knowledge, and it is the role of educators to elaborate such networks. In such a network, the edges are not only links between information; the edges contribute to the meaning of the knowledge, and each edge or link brings an 'added value' to the network of knowledge. Each item of knowledge is enriched by the links it has with other pieces of knowledge.

Conversely, knowledge, which was up to now stored in books and in libraries, is now networked; the networked dimension of knowledge is made possible because knowledge is in a digital form. Because knowledge is now networked, it is more rich and complex.

Complexity and networking are linked concepts. In a more and more complex world, networking as a tool enables us to address complexity and complex objects. Networking helps us to understand better the growing complexity of the world. Therefore, networking is profoundly linked to the evolution of Society: more complex implies more networked, and more networked makes it more complex.

As an example of complexity in the field of education, the French sociologist Morin(2001) suggests that the traditional disciplines can no longer be enough to address the complex problems of Society and Humanity. He proposes seven necessary kinds of knowledge for the education of the future:

- Detecting error and illusion. Teach the weaknesses of knowledge: what is human knowledge? Teach its errors, its illusions. Teach how to know what to know is!

- Principles of pertinent knowledge. One must be able to take into account global and fundamental problems, in which partial and local knowledge will then be used. Knowledge cannot be split into disciplines. One must be able to consider the objects of knowledge in their context, in their complexity, in their whole.

- Teaching the human condition. Teach the unity and the complexity of human nature. This needs input from biology, from human sciences, from 
literature, from philosophy. Teach the relationship between the unity and the diversity of what is human.

- Global identity. Teach knowledge at a world-wide level. Teach the history of the planetary era, teach the solidarity between all the parts of the world.

- Confronting uncertainties. Sciences have established a lot of certainties, but they also have revealed many uncertainties. Teach the uncertainties in physics, in biology, in history.

- Understanding each other. Teach understanding; understanding in all its meanings, mutual understanding between human beings. And teach what misunderstanding is. It is a crucial basis for peace education.

- Ethics for the human genre. Teach the world. Teach the ethics of humanity preparing citizens of the world. Teach how democracy relates to the mutual control between society and individuals.

Such a new 'curriculum', in which traditional disciplines do not disappear but are included in a different way, illustrates how knowledge is interlaced, and needs a networked approach.

Not only knowledge is profoundly changed by ICT, but also the way one can access knowledge. Knowledge is no longer only in books, in libraries, in the Teacher's head; it is available in many places, at any time, and it is distributed in a networked form. Being able to access knowledge means being able to find appropriate paths in complex networks. But the wide and easy availability of knowledge brings new difficulties: knowledge, as it is, is not necessarily validated, its accuracy is not visible, and the user needs to be able to sort and validate the knowledge he/she finds; knowledge is not clearly different from information in the resources available, and the user has to be able to find appropriate knowledge among the huge amount of information. Here is clearly a major role for the Teacher, not only to deliver knowledge to the pupils, but to help them find accurate knowledge, to help them circulate in the network of knowledge.

\section{COLLECTIVE INTELLIGENCE}

In the networked society, intelligence is no longer only an individual matter. Traditionally, education aims at developing the individual intelligence of the students. But now, society needs a new kind of intelligence, a collective intelligence. This is necessary in many professions, this is necessary for citizenship. Collective intelligence is not only the addition of individual intelligences; there is a specific collective dimension in this new intelligence. 
Collective intelligence can be approached through a network of individual intelligences, individual intelligences, with relationships which make them complementary, which enrich each of them and make them more efficient, and which help solve problems which need not only individual intelligence but a collective one.

Lévy (1994) has shown how the Internet is linked with the development of a collective intelligence. He has described on many occasions how the Internet is mainly a tool, the more recent we found for perfecting our intelligence through cooperation and exchange ... The true revolution of Internet is not at all a revolution of machines, but of communication between human beings ... the Internet enhances our capacity for collective learning and intelligence ... Each community realises that it is one of the dimensions of the production of human sense ... the Internet forces us to experiment new ways of being together ... The ethic of collective intelligence, consisting in interlacing different points of view ...

The collective intelligence is made possible because communication is possible, because people are networked, because everybody can be connected to everybody. Connectivity makes collective intelligence exist; this is why De Kerckhove (2001) speaks about 'connective intelligence'.

The classroom is the first place were collective intelligence can be built and used. This is also a major role for the teacher.

\section{NEW PROFESSION, NEW PROFESSIONS}

A lot of new competencies are needed for teachers: competencies linked with technology (they must be able to use the new tools, to make them work), competencies linked with the new pedagogical possibilities (they have to be 'pedagogical engineers'), competencies linked with the new knowledge and the new networked form of knowledge, competencies linked with the new expectations Society has towards teachers. Adding together all these competencies, it could seem impossible to provide any teacher with all of them. Clearly, the teacher's competency can no longer be described only with a list of definite abilities. The teacher's competency needs to evolve and adapt all his/her career long. It is a collective competency: we need teams having a set of competencies, not necessarily each teacher having all of them.

ICT has certainly increased the competencies teachers need; but there are core expectations from Society towards teachers. The French National Commission for Unesco(Cornu, 2001) has studied the changes in the teaching profession. The teaching profession is based on the 'four pillars of Education': Learning to know, Learning to do, Learning to live together and 
learning to live with others, Learning to be. The teaching profession takes place in a world marked by increasing tensions, such as the tension between local and global, the tension between tradition and modernity, the tension between short term and long term, the tension between spiritual and material values. Education, in most countries, is facing new dimensions, with the increasement of democratisation, complexification and globalisation. In such a context, teachers have two major roles:

- Forming citizens in a world marked by change and dominated by the ephemeral; transmitting the basic values of society and the universal values of humanity.

- Instilling knowledge, when knowledge has changed and accessing knowledge has changed.

Clearly the teachers' competencies and activities have been increased, and the profession is getting more and more complex. But, rather than adding and adding new expectations, one could say that ICT and the variety of possibilities it permits confirm the essential and core role of the teacher. Since Socrates, the teacher has been the mediator between knowledge and the student; since Socrates, the face-to-face relationship between the teacher and the pupil has been the core role of the teacher. Balle (1999) says that ICT does not profoundly affect the status of the teacher, nor the fundamental vocation of school, but enables them to do better the best things that they do and that only they can do.

The human dimension of the teaching profession appears to be essential, and this dimension cannot be replaced by technology. But the human dimension can be supported and enhanced by technology, since ICT reinforces the possibilities of communicating and individualizing teaching.

Thus, even if ICT provokes profound perturbations in the profession of the teacher and his/her daily activity, the core characteristics are stable. If there is a 'new teaching profession', it is not in the fundamental mission, but in the way the profession is practised every day, in the tools and resources available, in the diversity of possible pedagogical methods.

But besides the teaching profession, new professions are appearing in Education: engineers and technicians, technological assistants, pedagogical assistants, educators of different types ... It is too early to describe precisely these new professions, which we can see around us in schools and universities. The teacher will not remain the only educative actor; recentered on his/her core role, he/she will be surrounded and assisted by other kinds of professionals. 


\section{NEW VIRTUAL LEARNING ENVIRONMENTS}

Being a teacher in the networked society needs specific tools and environments.

First of all, teachers need to be networked, at different levels: at the local level (teachers in a given school), at other kinds of levels (for example national level, or teachers in a given discipline, or teachers in international networks...) and more generally in the 'global network'. Networking enriches the resources available for the teacher, networking enhances collaborative working among teachers, and networking enriches the possibilities for teachers to interact with their pupils. One can see how many groups are formed for teachers to cooperate: discussion forums, interest groups, etc.

Among the new tools available for teachers, virtual learning environments are essential. One can see them appear under different names: digital schoolbag, digital campus, virtual schools, digital working environments ... They aim at globalizing all the activities of schools' actors: teachers, students, but also parents, administrators, etc. They provide different types of facilities:

- Resources: accessing resources, organizing and storing resources, creating and producing resources, etc.

- Communication tools: e-mail, Intranet, access to the Internet...

- Collaborative working tools.

Most such environments are conceived on a modular basis, so that they can be enriched continuously, and can interoperate with other systems. They take into account 'nomadism', making possible complementarity between activities at school and activities out of the school. They have two major interests:

- providing school actors with new tools, adapted to the new needs of a 'networked' education, and anticipating the future evolutions of education;

- making concrete the 'unity' of education: traditionally, pedagogy is separated from administration, and school is separated from home. Such environments consider the pupil's life as a whole, school's life as a whole, and this enriches the complementarity of different situations.

Virtual learning environments are based on a plurality of actors and on a plurality of activities. They illustrate some of the evolutions in the teaching profession. 


\section{SCENARIOS FOR THE FUTURE}

In a recent study, the OECD (2001) has developed six scenarios for the school of the future up to 2020. The scenarios are clustered into three categories: 'Attempting to Maintain the Status Quo', 'Re-schooling' and 'De-schooling'. Two aspects are important:

- None of these scenarios will happen in its pure form, the reality will be more complex and mixed; but the six scenarios give trends, which we must take into account;

- There is no inevitability in the future: actors must decide where they want to go, and such scenarios may help in decision-making.

It is useful to consider, for each of the scenarios, what happens for teachers and the teaching profession. In this paragraph, we borrow some sentences from the OECD document.

The 'status quo' scenarios consider that the basic features of existing systems are maintained into the future.

- In the first scenario, 'Bureaucratic School Systems Continue', school systems continue to be strong, with a pressure towards uniformity, and resistance to radical change. Individual classroom and teacher models remain dominant. The use of ICT continues to grow without changing schools' main organisational structures. In such a scenario, teachers form a strong corps, generally with the status of civil service. The evolution of the role and status of teachers in such a scenario is just the continuation of the present situation. Teaching is considered as an 'individual art'.

- In the second scenario, teacher shortage leads to a crisis: 'Teacher exodus - The 'meltdown scenario'. The teaching profession is rapidly ageing, and gets less and less attractive. ICT may appear as a possible response to teacher shortage. Salaries increase in order to attract more teachers, but this has detrimental consequences for investments in areas such as ICT and physical infrastructure. In this scenario, there is a major difficulty in recruiting enough teachers, and the market of 'school at home' is developing, with new types of professionals.

The 're-schooling' scenarios are based on major investments and widespread recognition for schools and the professionals, with a high priority accorded to both quality and equity.

- In the scenario 'Schools as Core Social Centres', the focus is on socialisation goals and schools in communities. School is recognized as the most effective bulwark against social, family and community fragmentation. It is now heavily defined by collective and community tasks. This leads to extensive shared responsibilities between schools and other community bodies. The focus of learning broadens with more explicit attention given to 
non-cognitive outcomes, values and citizenship. Significant investments would be made to update the quality of premises and equipment in general and to open school facilities to the community. ICT is used extensively, especially its communication capabilities. In this scenario, teachers have a high-level status and various types of contracts. Around them would be many other professionals, community players, parents, etc.

- The other scenario: 'Schools as Focused Learning Organisations', has a stronger knowledge orientation. New forms of evaluation and competence assessment flourish. ICT are used extensively alongside other learning media. Schools look like 'learning organisations'. Flourishing research on pedagogy and the science of learning is systematically applied. Schools management uses teams, networks and diverse sources of expertise. Teachers enjoy favourable conditions and are highly motivated, with strong emphasis on R\&D, continuous professional development, group activities, networking (including internationally). Contractual arrangements might well be diverse, with mobility in and out of teaching. We meet the concept of 'networked teachers in a networked society'.

The two 'de-schooling' scenarios see the dismantling of school systems.

- In the scenario 'Learning Networks and the Network Society', new forms of co-operative networks come to predominate. Dissatisfaction leads to the abandonment of schools in favour of a multitude of learning networks, quickened by the extensive possibilities of powerful, inexpensive ICT. The emerging 'network society' leads to the dismantling of school systems. Greater expression is given to learning for different cultures and values through networks of community interests. Small group, home schooling and individualised arrangements become widespread. There would be a substantial reduction in public facilities and institutionalised premises for schools, but major investments in ICT could be expected. In such a scenario, there is no longer reliance on particular professionals called 'teachers': the demarcations between teacher and student, parent and teacher, education and community, blur and sometimes break down. New learning professionals emerge, whether employed locally to teach or as consultants (home teaching, educational 'hot lines', office consultancy...).

- The scenario 'Extending the Market Model' is the result of competitive mechanisms. Existing market features in education are significantly extended as governments encourage diversification in a broader environment of market-led change. Many new providers are stimulated to come into the learning market. The most valued learning is importantly determined by choices and demands. There is a substantially reduced role for public education authorities, and entrepreneurial management modes are more prominent. In such a situation, new learning and educational professions are created in the market. 
Such scenarios show different trends for possible evolutions of the teaching profession. Will teaching be mainly an art, a vocation, or a profession? How will the shortage of teachers affect the nature of the profession? Will the school be reinforced, or will it disintegrate? Will education focus mainly on knowledge and disciplines, or on values and citizenship? How will the status of teachers evolve? How will the market affect the teaching profession? Asking such questions may help us master the evolution.

\section{TEACHERS AND NATIONAL POLICIES}

It is clear that teachers play a major role in national educational policies.

The expectations that society has of teachers are changing and growing in complexity. National policies have to take this into account and to express these expectations. They also have to enable teachers to complete their tasks and roles in relation to these expectations.

The social status of teachers is a key element of a national policy; not only teachers' salaries, but also the way they are considered in society, the role they have as public service agents.

Will teachers mostly remain in the public service, or shall we see more and more private educational actors? A national policy must address this type of question.

And national policy must also accompany the teaching profession in the changes due to ICT. For example, ICT creates new tasks for teachers; they do not only have to be in the classroom with their pupils, then at home for preparing their lessons, but they have a wide diversity of different activities: team work with colleagues, being available for pupils, physically or at a distance through e-mail or other means of communication, working in small groups with pupils, spending time to design digital resources, etc. The official duties of a teacher usually do not take these new tasks into account, and as a consequence only the most motivated teachers spend time on such innovative tasks. In the future, precise descriptions of teachers' tasks and precise description of their obligations will be needed. There will not be only one way to be a teacher, but a diversity in the possible activities for a teacher. Making explicit this diversity, showing the different ways of being a teacher, showing how a teacher can take part in innovation, increasing the social status of the teachers, are necessary items for reducing the shortage of teachers in the future.

It is interesting to note that most of these points were addressed in the 'Recommendation Concerning the Status of Teachers' (Unesco, 1966), adopted by the Unesco Special Intergovernmental Conference on the Status of Teachers in ... October 1966! 
The political dimension of the teacher's mission must not be considered only at the national level. Globalisation and internationalisation also occur in the Education field, and lead to major questions, both political and ethical. International concerns about education (such as the one expressed by the Dakar Forum - 'Education for All') should also influence the teaching profession, and help teachers to take into account the questions that are posed at the global level.

\section{CONCLUSION...}

The changes in Society, and particularly those due to ICT, provoke major changes in the teaching profession. Being a teacher cannot now be considered only as an art, as a vocation; it is more and more a profession, with all the dimensions linked with such a concept: working conditions, status, preparation and pre-service training, professional development and in-service training, innovation, etc.

Teachers have gone through a progression(Unesco/IFIP, 2000): ICT has first emerged as new concepts, new tools, new resources, with no evidence that it could be used in education; then they started applying ICT to their professional activity, looking at how teaching could be changed by the use of new tools. In a third phase, teachers went to the integration of ICT into education. But now we are entering the phase of transformation. ICT can no longer be simply considered as a collection of tools for improving teaching and learning; a profound transformation has started, and teachers are the main agents of this transformation.

\section{REFERENCES}

Balle, F. (1999). Les NTIC: Outils au service de la formation à l'enseignement. Les Technologies de l'Information et de la Communication et Leur Avenir en Éducation, XXVII(2).

Cornu, B. (2001). Winds of Change in the Teaching Profession. Paris: French National Commission for Unesco.

De Kerckhove, D. (2001). Principles of Cyberarchitecture. Boston: Birkhäuser.

Lévy, P. (1994). L'Intelligence Collective. Paris: La Découverte.

Merckelbach, S. \& Dupas, P. (2002). L'Araignée, la Girafe et les Réseaux de Proximité. Freiberg: Ordinata.

Morin, E. (2001). Seven Complex Lessons in Education for the Future. Paris: Unesco Publishing.

OECD/CERI (2001). What schools for the future? Paris: OECD.

Unesco (1966). Recommendation Concerning the Status of Teachers. Paris: Unesco.

Unesco/IFIP (2000). Information and Communication Technology in Secondary Education: a curriculum for schools. Paris: Unesco. 